\title{
Environmental Pollution due to the Operation of Gasoline Engines: Exhaust Gas Law
}

\author{
Koffi Sagna $^{1,}{ }^{\text {* }}$, Komi Apélété Amou ${ }^{1}$, Tchamye Tcha-Esso Boroze ${ }^{1}$, Djima Kassegne ${ }^{1}$, \\ Amah d'Almeida ${ }^{1,2}$, Kossi Napo ${ }^{1}$ \\ ${ }^{1}$ Laboratory on Solar Energy, Physics Department, Sciences Faculty, University of Lomé, Lomé, Togo \\ ${ }^{2}$ Mathématics Department, University of Lomé, Lomé, Togo
}

\section{Email address:}

ksagna@univ-lome.tg (K. Sagna)

${ }^{*}$ Corresponding author

\section{To cite this article:}

Koffi Sagna, Komi Apélété Amou, Tchamye Tcha-Esso Boroze, Djima Kassegne, Amah d'Almeida, Kossi Napo. Environmental Pollution due to the Operation of Gasoline Engines: Exhaust Gas Law. International Journal of Oil, Gas and Coal Engineering. Special Issue: Computer-Aided Reservoir Characterization Methods. Vol. 5, No. 4, 2017, pp. 39-43. doi: 10.11648/j.ogce.20170504.11

Received: June 9, 2017; Accepted: June 23, 2017; Published: July 17, 2017

\begin{abstract}
We investigate the law of exhaust gases in order to control the pollution that is increasingly present in our daily lives. Pollution is a degradation of the environment by non-natural materials in several environments constituting our universe. Thus, it intervenes as well in water, in the air as in the soil. It is mostly due to human activities, especially in urban areas and industrial areas, and the massive use of automobiles based on gasoline engines. The results show that this pollution is due in part to the existence of the mass and thermal discontinuity characterized by shock waves which occur during the evaporation process, precursor of the incomplete combustion in the combustion chamber of the engines [1,2]. By analytical approach, we establish in this paper the law $\varphi$ of the exhaust gases in poor and rich reaction media during combustion in the combustion chambers of gasoline engines in order to propose the ranges of adequate proportions of additive elements to the petrol. These engines, when operating, release various gaseous pollutants such as: carbon dioxide, oxides of carbon and nitrogen, unburnt hydrocarbons, which undoubtedly contribute to the nuisance and pollution of our environment.
\end{abstract}

Keywords: Exhaust Gas, Environment, Pollution, Exhaust Law, Gasoline Engine

\section{Introduction}

The successive tightening of the regulation regulating polluting emissions has made it possible to reduce significantly the contribution of the automobile to air pollution, despite the perpetual growth of its fleet. For manufacturers, research on the reduction of polluting emissions has become a priority in the development of future vehicles. The use of exhaust after treatment devices such as catalytic converter, $\mathrm{NO}_{\mathrm{x}}$ trap or particulate filter reduces polluting emissions, but these will be insufficient to meet future standards. An effort is therefore needed to limit the formation of pollutants at the source, i.e it is necessary to improve combustion efficiency [3].

The air pollution due to the substances emitted by gasoline engines are very numerous and form, a true cocktail of pollutants in the air (Oxides of carbon $\left(\mathrm{CO}\right.$ and $\left.\mathrm{CO}_{2}\right)$, oxides of nitrogen $\left(\mathrm{NO}_{\mathrm{x}}\right)$, Volatile Organic Compounds (VOCs), including hydrocarbons, particulates, heavy metals, tropospheric ozone). The pollutants mentioned above distinguish those contained in exhaust gases or from vehicles and the roadway or exhaust gases or evaporated from fuels on the one hand. On the other hand, we can distinguish directly emitted pollutants which are called primary pollutants; some of these photochemical pollutants, also called secondary pollutants.

To understand the formation and dispersion of pollutants, we note that carbon monoxide, a potent toxicant can block the fixation of oxygen by red blood cells (anoxia), is emitted during the incomplete combustion of hydrocarbons: Combustion, carbon is first oxidized to carbon dioxide $\left(\mathrm{CO}_{2}\right)$.

If a new carbon atom is added to this molecule, under certain conditions of temperature and pressure, two carbon monoxide $(\mathrm{CO})$ molecules are formed. If there is sufficient 
oxygen present, the monoxide oxidizes again to carbon dioxide. If a carburetor is improperly adjusted, the lack of oxidant causes the production and emission of exhaust gases with higher $\mathrm{CO}$ "[4], ie carbon dioxide is emitted when there is combustion of hydrocarbons, whereas carbon monoxide is emitted essentially when this combustion is incomplete.

The catalytic converter allows, among other things, the oxidation of toxic carbon monoxide to carbon dioxide, much less dangerous. The diffusion of carbon monoxide is very rapid. It disappears rapidly as soon as one moves away from a source of emission [5]. This is because carbon monoxide has a density close to that of air.

The oxides of nitrogen $\left(\mathrm{NO}_{\mathrm{x}}\right)$, nitrogen $(\mathrm{N})$ and oxygen (O) react under the conditions of high temperatures and engine pressures to form nitrogen monoxide (NO). Once released to the atmosphere, nitrogen monoxide oxidizes to form nitrogen dioxide $\left(\mathrm{NO}_{2}\right)$ [6]. Monoxide is the most abundant in the atmosphere, accounting for about $95 \%$ of emissions. The nitrous oxide $\left(\mathrm{N}_{2} \mathrm{O}\right)$ is generated by the nitrogen present initially in the fuels; active in the troposphere, it is an active agent for attacking the stratospheric nitrogen layer $[6,7]$.

Volatile organic pollutants are also found. These organic pollutants consist of carbon and its combinations; among which are noted the hydrocarbons which are binary compounds consisting of carbon and hydrogen. Volatile organic pollutants are emitted either by evaporation at the pump, at the carburetor and reservoir (caused by temperature fluctuations), or by loss (splashing at the pump or level of the tank) exhaust. The specific composition of emissions of volatile organic pollutants, whether produced by combustion or evaporation, varies very strongly depending on the fuels and their additives. This is why gasoline or other fuel vehicles give different emission spectra. However, total emissions of volatile organic pollutants are equivalent because, if diesel vehicles emit much less volatile organic pollutants per kilometer, their releases contain a high concentration of the most reactive volatile organic compounds (aromatics, aldehydes and olefins) That diesel engines contribute significantly more to nitrogen formation [9].

Hydrocarbons often in the operation of gasoline engines, those polycyclic aromatics, are the most dangerous for health as carcinogens. These aromatic hydrocarbons consisting of several benzene rings ( 2 to 6 or 8 ) joined in various forms. The majority of polycyclic aromatic hydrocarbons originate from pyrolysis processes and in particular from the incomplete combustion of organic materials or carbon compounds [7].

Polycyclic aromatic hydrocarbons are mostly adsorbed on carbonaceous particles. They are also detected in the gaseous phase, in particular in the exhaust gases of gasoline engines; In this case, polycyclic aromatic hydrocarbons with the lowest molecular weight (up to 3 cycles), which are called light polycyclic aromatic hydrocarbons. Among the polycyclic aromatic hydrocarbons, benzo (a) pyrene is the most studied because it is particularly dangerous for health
[8]; It is emitted at practically the same rate by a gasoline vehicle [7].

Monocyclic aromatic hydrocarbons as Benzene, Toluene, Ethyl benzene and Xylene are monocyclic aromatic hydrocarbons. They are unburned hydrocarbons. Benzene is produced from the dealkylation of aromatics, so that even if its content is limited in the fuels, the presence of the aromatic compounds leads to its formation. Monocyclic aromatic hydrocarbons are the main volatile organic pollutants emitted by gasoline-powered traffic, especially since the introduction of new anti-detonators, aromatic hydrocarbons replacing tetraethyl lead. Monocyclic aromatic hydrocarbons are very hazardous to health $[10,11]$.

In this paper, the analytical study is carried out from the combustion balance equations in the combustion chambers of the engines in order to establish the law governing the production of exhaust gases. The establishment of this law of exhaust gases $(\varphi)$ will allow, after studying these characteristics, depending on the molar fraction of pollutants emitted and the richness of the reaction mixture; to propose the measures that will allow the control of the gaseous pollutants emitted during the operation of gasoline engines. The establishment of this law should be possible taking into account, on the one hand, the equilibrium constant of the couples $\left(\mathrm{CO}_{2} / \mathrm{CO}\right)$ and $\left(\mathrm{H}_{2} / \mathrm{H}_{2} \mathrm{O}\right)$ because the relative concentrations of the products of combustion depend on it and, on the other hand, of the balance of oxygen matter. The aim of this investigation is to find solution approaches to combat gasoline engine exhaust fumes.

\section{Methodology: Analytical Approach; Exhaust Laws}

Combustion studies on engines and vehicles frequently involve the relationship between the composition of the airfuel mixture and the exhaust gas [12]. After complete combustion of the fuel, carbon is normally in the form of carbon dioxide and hydrogen in the form of water. In reality, the composition of the final mixture is always much more complex. As a rich mixture, for example, the reaction system does not contain enough oxygen to allow full oxidation. In addition to the abovementioned species, carbon monoxide and hydrogen are formed. In any case, the products obtained can undergo a great number of subsequent reactions (dissociations, combinations), the degree of progress varies with pressure and temperature. Assuming thermodynamic equilibrium is reached, it is possible to calculate the final composition. In fact, the actual state of the exhaust gases is rarely that of equilibrium because several chemical reactions leading to this stable state occur with very low velocity and are therefore frozen at a certain temperature threshold. In practice, these are very complex and, moreover, unrealistic calculations are not carried out in view of the freezing. By considering only the main products $\left(\mathrm{CO}_{2}, \mathrm{CO}, \mathrm{H}_{2} \mathrm{O}, \mathrm{H}_{2}, \mathrm{O}_{2}\right.$ and $\mathrm{N}_{2}$ ), it is possible to determine an approximate composition of the exhaust gases. The data are then the 
elemental composition of fuel and wealth; we distinguish stoichiometric, poor or rich.

three cases according to whether the mixture is

Table 1. Composition of combustion products under conditions of thermodynamic equilibrium. Hydrocarbon $C_{n} H_{2 n}$, temperature 1000K, pressure 1 bar [12].

\begin{tabular}{llll}
\hline \multirow{2}{*}{ Combustion Products } & Mole fraction & $\boldsymbol{\varphi}=\mathbf{1 , 2 0}$ \\
\cline { 2 - 4 } & $\boldsymbol{\varphi}=\mathbf{0 , 8 0}$ & $\boldsymbol{\varphi}=\mathbf{1 , 0 0}$ & $1,17.10^{-1}$ \\
$\mathrm{CO}_{2}$ & $1,06.10^{-1}$ & $1,31.10^{-1}$ & $3,20.10^{-2}$ \\
$\mathrm{CO}$ & - & $3,99.10^{-7}$ & $1,07.10^{-1}$ \\
$\mathrm{H}_{2} \mathrm{O}$ & $1,06.10^{-1}$ & $1,31.10^{-1}$ & $4,23.10^{-2}$ \\
$\mathrm{H}_{2}$ & - & $5,74.10^{-7}$ & - \\
$\mathrm{O}_{2}$ & $3,97.10^{-2}$ & - & $6,94.10^{-1}$ \\
$\mathrm{~N}_{2}$ & $7,39.10^{-1}$ & $7,30.10^{-1}$ & \\
\hline
\end{tabular}

In a stoichiometric mixture $(\varphi=1,00)$, the normal combustion products are only $\mathrm{CO}_{2}$ and $\mathrm{H}_{2} \mathrm{O}$; their composition are given by the equation:

$$
\mathrm{CH}_{y} \mathrm{O}_{z}+\left(1+\frac{y}{4}-\frac{z}{2}\right)\left(\mathrm{O}_{2}+3,78 \mathrm{~N}_{2}\right) \rightarrow \mathrm{CO}_{2}+\frac{y}{2} \mathrm{H}_{2} \mathrm{O}+3,78\left(1+\frac{y}{4}-\frac{z}{2}\right) \mathrm{N}_{2}
$$

In the lean mixture $(\varphi<1,00)$, the exhaust gases also contain residual oxygen; the combustion is then written as the following equation:

$$
\mathrm{CH}_{y} \mathrm{O}_{z}+n\left(\mathrm{O}_{2}+3,78 \mathrm{~N}_{2}\right) \rightarrow \mathrm{CO}_{2}+\frac{y}{2} \mathrm{H}_{2} \mathrm{O}+\left(n-1-\frac{y}{4}+\frac{z}{2}\right) \mathrm{O}_{2}+3,78 n N_{2}
$$

With:

$$
n=(1+y / 4-z / 2) / \varphi
$$

In a rich mixture $(\varphi>1,00), \mathrm{CO}_{2}, \mathrm{CO}, \mathrm{H}_{2} \mathrm{O}$ and $\mathrm{H}_{2}$ are formed simultaneously and the combustion equation becomes:

$$
\mathrm{CH}_{y} \mathrm{O}_{z}+n\left(\mathrm{O}_{2}+3,78 \mathrm{~N}_{2}\right) \rightarrow a C \mathrm{O}_{2}+(1-a) \mathrm{CO}+b \mathrm{H}_{2} \mathrm{O}+\left(\frac{y}{2}-b\right) \mathrm{H}_{2}+3,78 n \mathrm{~N}_{2}
$$

The relative concentrations of combustion products are linked by this following equilibrium reaction:

$$
\mathrm{CO}_{2}+\mathrm{H}_{2} \rightleftarrows \mathrm{CO}+\mathrm{H}_{2} \mathrm{O}
$$

In fact, experience shows that the composition of the gas, measured at the exhaust, is, in any case, a solidification of the previous reaction (equation (5)) at a temperature of about $1700 \mathrm{~K}$, this leads to a value of the equilibrium constant $K$ which is close to 3.8 [12].

$$
K=\frac{[\mathrm{CO}]\left[\mathrm{H}_{2} \mathrm{O}\right]}{\left[\mathrm{CO}_{2}\right]\left[\mathrm{H}_{2}\right]}=\frac{(1-a)(b)}{a\left(\frac{y}{2}-b\right)}=3,8
$$

By using the oxygen mass balance, we can write:

$$
2 n+z=2 a+(1-a)+b=a+b+1
$$

It is possible to determine the numerical values of $a$ and $b$ and to calculate the relative concentrations of the effluents.

From the dosage of a reduced number of constituents of the exhaust gases, it is possible, taking account of certain legitimate assumptions and approximations, to calculate the richness $\mathrm{T}$ of the initial mixture. Several methods have been proposed [12]; one of the most used, "total $\mathrm{CO}_{2}$ ", consists of carrying out a carbon assessment.

From equations (2) and (3), we obtain in a lean mixture:

$$
T=\frac{100}{1+\left(n+\frac{z}{2}-1-\frac{y}{4}\right)+3,78 n}
$$

After simplification, equation (8) becomes:

$$
T=\frac{100}{4,78 n+\left(\frac{z}{2}-\frac{y}{4}\right)}
$$

And in rich mixture:

$$
T=\frac{100}{1+\left(\frac{y}{2}-b\right)+3,78 n}
$$

In the case of the lean mixture, the following equation is obtained after demonstration:

$$
\varphi=\frac{4,78 T\left(1+\frac{y}{4}-\frac{z}{2}\right)}{100+T\left(\frac{y}{4}-\frac{z}{2}\right)}
$$

It is the law of exhaust for a poor mixture. This law, considering equation (10), becomes after demonstration for a rich mixture:

$$
\varphi=\frac{3,78 T\left(1+\frac{y}{4}-\frac{z}{2}\right)}{100-T+\left(b-\frac{y}{2}\right)}
$$

The determination of the expression of $b$ makes it possible to completely determine the expression of the law of escape for a rich mixture. Taking into account equation (6) reported in equation (7), we obtain $b$ that, it is the solution of the following equation:

$$
2,8 b^{2}-\alpha b+\beta=0
$$

when: 


$$
\left\{\begin{array}{c}
\alpha=3,8 n y+1,9 y z-1,9 y \\
\beta=5,6 n+2,8 z+1,9 y-1,8
\end{array}\right.
$$

$b$ being unique and positive then its value is determined when the following condition is fulfilled:

$$
\beta^{2}=11,2 \alpha
$$

We obtain after calculation:

$$
b=n+0,5 z+0,34 y-0,32
$$

Finally, equation (16) in equation (12) gives the exhaust gas law for a rich mixture by the following equation:

$$
\varphi=\frac{100-T-0,16 y+0,5 z-0,32}{(1+0,25 y-0,5 z)(3,78 T-1)}
$$

This exhaust gas law, which characterizes the proportion of gaseous pollutants escaping during the operation of gasoline engines, should be mastered when its function is tending rapidly towards a horizontal bearing. The control of this law will thus better allowed to control the rate of pollutants emitted into the environment.

\section{Results Discussion}

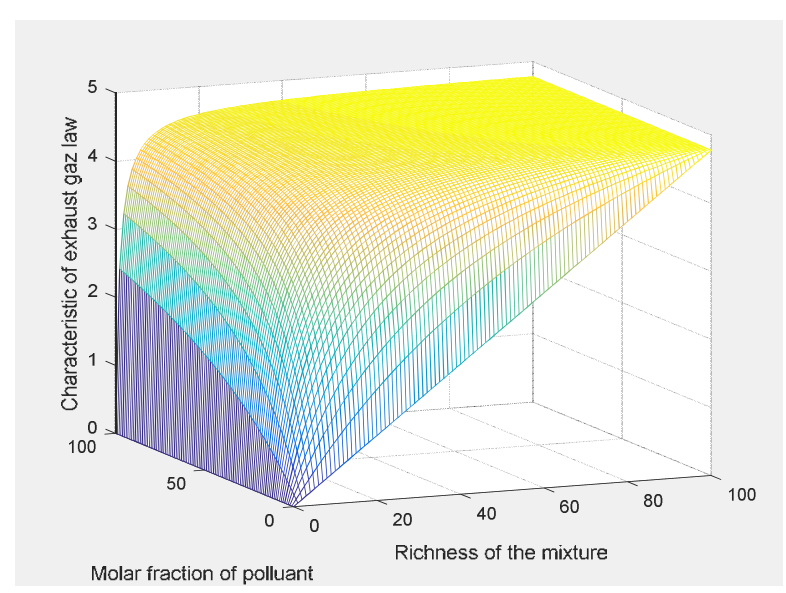

Figure 1. Characteristic of the law of the exhaust gas versus the richness of the reaction mixture and the molar fraction of pollutant (Poor mixture).



Figure 2. Characteristic of the law of the exhaust gas depending on the richness of the reaction mixture and the molar fraction of pollutant (rich mixture).
The figure 1 corresponds to the graphic representation obtained by plotting the exhaust gas law concerning when the reactive mixture is poor and the figure 2 when the reactive mixture is rich. Analyze of these figures allowed us to understand how and when they can be easily possible to control the environment degradation due to the emitted pollutants during the engines operation. First, on the one hand, it can be seen from the analytical study according to FIG. 1, that the evolution of the exhaust gases law depends on the richness of the reaction mixture and the molar fraction of pollutant. When the mixture is lean, the level of pollutant emitted during the operation of gasoline engines is controlled, especially since the characteristics of the law in this case tend asymptotically towards a fixed pollutant rate that is between 4.5 and $5 \%$. Knowing the limit of the pollutant rate value could help to predict the appropriate rate of the reaction mixture richness. On the other hand, when the mixture is rich (FIG. 2), the pollutant level emitted during operation of the gasoline engine is practically zero, however, we note a peak pollutant emission when the rate of the mixture's richness is around $22 \%$. We could also remark that after this rate corresponding to the peak of pollutant, when the richness of the reaction mixture remains higher than $22.5 \%$, the pollutant emitted during the operation of the engine remains virtually nil. Nevertheless, it would be more economical and cheaper, to fix the proportion of the richness of the reaction mixture already around a value which is lower than that corresponding to the peak polluting emission $(22 \%)$.

\section{Conclusion}

We note in this paper that in order to control the level of pollutant emitted during the combustion process when the gasoline engines are operating, it would be enough, on the one hand, when the mixture is poor, to use some additives in a reasonable proportion at around $4.5 \%$. K. Boussouara [13] proposes that nitrous compounds or peroxides used as additives in small quantities would introduce already oxidized and unstable molecules which would substantially lower the level of pollutants emitted. On the other hand, when the mixture is rich, it would simply be necessary to control the value of the richness of the mixture, which should always be below $22 \%$.

\section{References}

[1] K. Sagna, A. d'Almeida, A study of droplet evaporation, paper published in American Journal of Moderne Physics (AJMP), Vol. 2, No. 2, 2013, pp. 71-76. doi:10.11648/j.ajmp.20130202.17.

[2] K. Sagna, A. d'Almeida, Supercritical evaporation of a drop, paper published in International Journal of Research in Engeneering and Science (IJRES), ISSN (Online): 2320-9364, (Print): 2320-9356, www.ijres.org Volume 2 Issue 7 ||July. 2014|| PP.41-47. 
[3] L. Landry, 'Etude expérimentale des modes de combustion essence sous forte pression et forte dilution', Thèse de doctorat de l'Université d'Orléans, Spécialité Mécanique et Energétique, 2009.

[4] M. Schütz, 1995, Environnement et Pollution- Comment mesurer? Comment réagir? Publitronic, Nieppe, 253p.

[5] G. Escourrou, 1996, Transports, contraintes climatiques et pollution, coll. Mobilité Spatiale, SEDES, Paris, 172p.

[6] C. Parmentier, J. P. Garrec, 1994, Impact de la pollution atmosphérique le long des routes et autoroutes sur la végétation environnante, Utilisation de la bioindication végétale, Synthèse Bibliographique, INRA de Nancy.

[7] P. Degobert, 1992, Automobile et Pollution, Editions Technip, Paris 516p.

[8] Société Française de Santé Publique, 1996, p. 105.
[9] OCDE, 1995, la pollution des véhicules à moteur - Stratégies de réduction au-delà de 2010, Les éditions de l'OCDE, Paris, $148 \mathrm{p}$.

[10] Argopol, 1995, Campagne de mesure qualité de l'air: arrière de Chamant. SYNTHE2. DOC, SANEF. $135 \mathrm{p}$.

[11] R. S. Spindt, (1965) Air-Fuel Ratios from Exhaust Gas Analysis. SAE Technical Paper 650507. http://dx.doi.org/10.4271/650507.

[12] J. C. Guibet, Carburants et Moteurs, Technologies - Energie Environnement, tome 1, Nouvelle Edition, 1997; Editions Technip, 27 Rue Ginoux 75737 Paris cedex 15.

[13] K. Boussouara, 'Etude des émissions polluantes et des moyens de pollution dans les moteurs à combustion interne', Thèse de doctorat en Science en Génie Mécanique de l'Université de Constantine, option: Energétique; 2010. 